\title{
Erratum to: Phenylephrine Pharmacokinetics and First-Pass Metabolism: What Is an Ideal Pharmacokinetic Surrogate?
}

\author{
Nuggehally R. Srinivas ${ }^{1}$
}

Published online: 26 October 2015

(c) Springer International Publishing Switzerland 2015

\section{Erratum to: Clin Drug Investig DOI 10.1007/s40261-015-0341-3}

A Published-Ahead-of-Print version of this article was made available online on 28 September 2015. Errors have subsequently been identified in the original version of the article, and the following corrections should be noted:

First paragraph, Line 6, cited authors' names, which previously read:

Gellote and Zimmerman

Should read:

Gelotte and Zimmerman

Fourth paragraph, Line 6, cited authors' names, which previously read:

Gellote and Zimmerman

Should read:

Gelotte and Zimmerman

Last paragraph, Line 1, cited authors' names, which previously read:

Gellote and Zimmerman

Should read:

Gelotte and Zimmerman

The online version of the original article can be found under doi: 10.1007/s40261-015-0341-3.

Nuggehally R. Srinivas

srini.suramus@yahoo.com

1 Drug Development, Suramus Bio, 29th Main, 10th Cross, JP Nagar I Phase, Bangalore, Karnataka 560078, India
Reference 1, which previously read:

Gellote CK, Zimmerman BA. Pharmacokinetics, safety, and cardiovascular tolerability of phenylephrine $\mathrm{HCl} 10$, 20 , and $30 \mathrm{mg}$ after a single oral administration in healthy volunteers. Clin Drug Investig. 2015;35:547-58.

Should read:

Gelotte CK, Zimmerman BA. Pharmacokinetics, safety, and cardiovascular tolerability of phenylephrine $\mathrm{HCl} 10$, 20 , and $30 \mathrm{mg}$ after a single oral administration in healthy volunteers. Clin Drug Investig. 2015;35:547-58. 